\title{
Research about the Combustion Synthesis Welding of U75V Rail Steel
}

\author{
Shuzhen $\mathrm{Li}^{\mathrm{a}}$, Bolin $\mathrm{He}^{\mathrm{b}}$, Kang Wei ${ }^{\mathrm{c}}$, Zongmin $\mathrm{Li}^{\mathrm{d}}$ \\ School of Mechanical \& Electrical Engineering, East China Jiaotong University, Nanchang 330013, \\ China \\ a13870955601@163.com, bhebolin@163.com cjiangmh28@163.com, d823987026@qq.com
}

Keywords: CS welding technology; combustion synthesis; microstructure

\begin{abstract}
As a new welding method, combustion synthesis welding technology caused widespread concern at home and abroad in recent years. The combustion synthesis technology, the concept of combustion synthesis welding, classification, welding process characteristics and influence factors were introduced. The combustion synthesis welding of U75V rail steel was carried out. The microstructure, hardness and strength of welded joint was tested and analyzed.
\end{abstract}

\section{Introduction}

Combustion synthesis technology is also called self-propagating high-temperature synthesis technology, abbreviated as SHS. It is a new technology by using chemical reaction exothermic and self-conductive material preparation. When the reactants are ignited, the reaction will automatically transmit from the one end to the other side until the end of the reaction. Solid flame was first found by the former Soviet Union chemical physics research institute Borovinskaya and Merzhanov [1] in researching combustion of $\mathrm{Ti}$ and $\mathrm{B}$. It was then named self-propagating high-temperature synthesis from the angle of combustion. So far, CS technology have penetrated into many fields, such as materials science and engineering, physics, chemistry, metallurgy, machinery science and engineering, etc. It has been widely studied and rapid development whether in theory or in application [2-6]. The results of their research can be broadly divided into the following six aspects: CS powder (powder prepared directly by CS method), CS densification, CS welding, CS sintered CS metallurgical and CS vapor transport coating.

\section{A brief description of the combustion synthesis of welding}

Synthesis welding and its classification. The Combustion synthesis (CS) welding is a novel processing technology in which its exothermic reaction heat serves as welding heat source and its reaction product serves as welding agent.

According to the different classification standards, CS welding has different classification criteria. According to the combustion wave propagation in different ways, CS welding can be divided into self-propagating way (ignition at one end of the blank, so that the flames spread from one end to the other end in the form of a transmission wave) and the heat explosion type (ignition all the blank, simultaneously throughout combustion and chemical reactions). Self-propagating combustion wave in the combustion process is spread from one end to another end, and it requires longer time than heat explosion. As time difference, the temperature and the heated area of the base material, most of the reaction products are porous and loose, so thermal explosion mode is used CS welding in the application. One step welding and two steps welding method can be divided according to different welding base metal, the main difference is that the welding mother material or component is in situ synthesis of welding process at the same time for the former, the welding base metal which has been prepared before welding will be welded together by combustion synthesis for the latter. CS welding can be divided into CS welding and CS connection according to whether the liquid phase appears or not in combustion process. In addition, according to the whether the intermediate transition layer appears or not in combustion process, CS welding can be divided into direct and indirect welding. 
The technological characteristics and influence factors of CS welding. Compared with the traditional welding technology, CS welding technology has the following features [7]. (1) when welding, The gradient material (FGM) can be synthesized by using the reaction raw material (configuration gradient solder) during the welding process for different materials so as to overcome the mismatch of the mechanics, chemical and physical properties. That is one end is affinity with metal, the other end is affinity with ceramic, the gradually transition of component and microstructure may solve the problem of residual stress in between metal and ceramic joint. (2) The reinforcing phase can be added to enhance the solder to form a composite material, such as reinforcing particles, whiskers, short fibers, etc. (3) It is convenient to carried out one step welding and two steps welding, in particular for one step welding, since it is possible to simultaneously generate the required material, thus greatly simplify the welding process. (4) In the reaction process, it can produce energy for welding and greatly save energy. In some of the highly exothermic system, it can achieve very high temperature which can not be reached by the conventional heating method, and high production efficiency can be obtained because the reaction time is very short. (5) The parent metal heat affected zone can be reduced because of fast exothermic reaction in the welding, avoid heat sensitive material of tissue destruction, be helpful for protecting the performance of the parent metal. (6) For the matrix of welding, it can use similar welding process of preparation of parent metal process, which can make the parent metal and solder has good physical and chemical compatibility.

As a complex system, there are many factors which have the effect on the combustion synthesis welding, such as the welding process of heating mode and rate, thickness of solder layer, igniting way and the combustion mode, the pressure of time and size, igniting temperature and combustion temperature, additives and soaking time, parent metal temperature and surface treatment condition, composition, particle size and its distribution of reaction raw material, and so on. The above CS welding factors are interdependent, which have great effect on the final performance of welded joints and microstructure, and should be considered synthetically during the analysis of weldment.

\section{The experiment of combustion synthesis welding}

Experimental Material. The tested material is U75V rail steel. The chemical composition is shown in Table 1 . The mechanical properties are listed in Table 2.

Tab.1 Chemical composition of U75V rail steel (wt\%)

\begin{tabular}{|c|c|c|c|c|c|c|}
\hline $\mathrm{C}$ & $\mathrm{Si}$ & $\mathrm{Mn}$ & $\mathrm{S}$ & $\mathrm{P}$ & $\mathrm{V}$ & $\mathrm{Nb}$ \\
\hline $0.71 \sim 0.80$ & $0.50 \sim 0.80$ & $0.70 \sim 1.05$ & $\leqslant 0.030$ & $\leqslant 0.030$ & $0.04 \sim 0.12$ & $\leqslant 0.010$ \\
\hline
\end{tabular}

Tab.2 Mechanical properties of U75V rail steel

\begin{tabular}{|c|c|c|c|c|}
\hline$\sigma_{\mathrm{m}} / \mathrm{MPa}$ & $\mathrm{HRC}$ & $\mathrm{Ak} / \mathrm{J}$ & $\delta / \%$ & $v$ \\
\hline 980 & 26 & 7.5 & 8.9 & 0.28 \\
\hline
\end{tabular}

The U75V rail steel was processed using a wire-cutting machine of DK7732M type (Suzhou, China). The specimens were cut into the special size and shape. The main welding materials were including chemical pure $\mathrm{Fe}_{2} \mathrm{O}_{3}$ power with particle size 100-200 mesh, which was made by Hengxing chemical reagent manufacturing co., LTD in Tianjing, and chemical pure Al power which was made by Shanghai east China reagent industry supply and marketing company, and the particle size is also100-200 mesh. The auxiliary welding material were including chemical pure Fe power with particle size 100-200 mesh, which was made by Tianjing Damao chemical reagent manufacturing co., LTD, and chemical pure $\mathrm{SiO}_{2}$ power which was made also by Tianjing Damao chemical reagent manufacturing co., LTD, and the particle size is 50-100 mesh.

Microstructure and hardness test. Microstructure after combustion synthesis welding was investigated by means of optical microscope of Axio Vert.A1 type (made by Carl Zeiss, Germany). The Rockwell hardness of the welded joint was tested by using HRC-150 type Rockwell hardness tester. The Rockwell hardness test was carried out three times for one specimen, and the average was 
obtained by the three values.

Tensile test. Tensile test specimens were cut from the welded rail sample, the selected position on the welded rail sample was shown in Fig.1. Tensile tests were carried out using AG-X 250 testing machine.

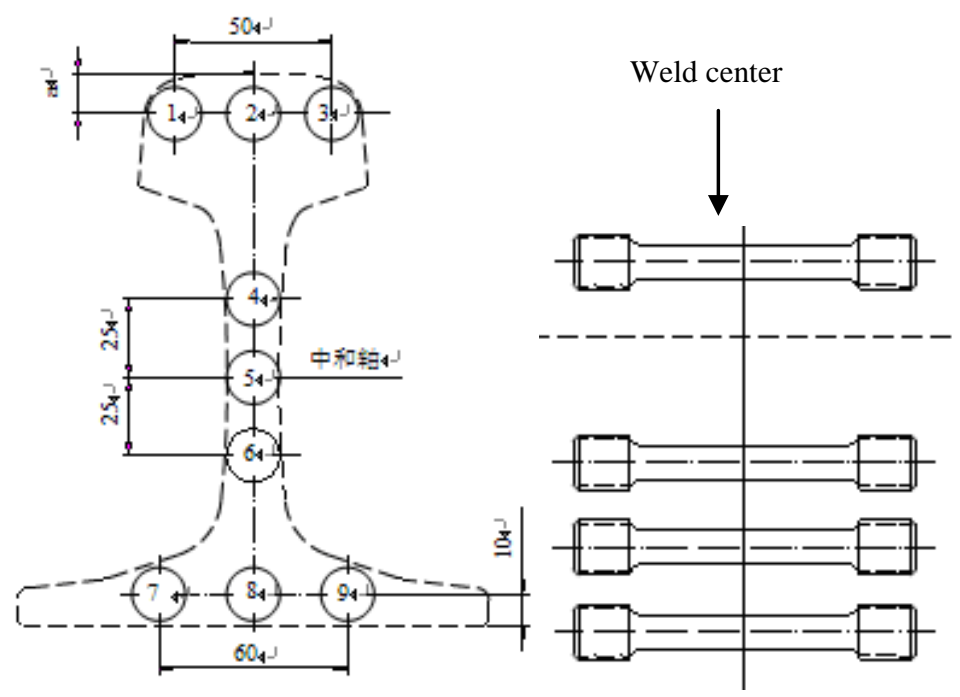

Fig.1 Tensile test specimen

\section{Test results and analysis}

Tensile test results and analysis. The tensile test results of combustion synthesis welding joint of U75V steel was shown in Table 3.

Table 3 Tensile test results of specimen

\begin{tabular}{|c|c|c|c|c|c|c|c|c|}
\hline Test item & 1 & 2 & 3 & 4 & 5 & 6 & 7 & 8 \\
\hline$\sigma_{\mathrm{m}} / \mathrm{MPa}$ & 751 & 782 & 769 & 746 & 701 & 772 & 681 & 784 \\
\hline$\delta / \%$ & 2.1 & 2.5 & 2.4 & 2.7 & 2.1 & 2.2 & 1.9 & 2.3 \\
\hline
\end{tabular}

According to the standard of TB/T 1632-1991, the tensile strength of the welded joint should great than $710 \mathrm{MPa}$, and the elongation should be great than $2.0 \%$. From the table 3 it can be seen that the average strength is $753 \mathrm{MPa}$, it is great than that of $710 \mathrm{MPa}$, the average elongation is $2.23 \%$, it is great than that of $2.0 \%$. From the table 3 it can be concluded that the welded joints are all satisfied.

Hardness test results and analysis. The hardness test results of base metal and combustion synthesis welding joint of U75V steel was shown in Table 4 and Table 5.

Table 4 Hardness test results of base metal specimen

\begin{tabular}{|c|c|c|c|}
\hline Specimens & Base metal/HRC & Average & Standard request \\
\hline 1 & 26.3 & & \multirow{2}{*}{27.0} \\
\hline 2 & 27.5 & \multirow{2}{*}{$26 \pm 2$} \\
\hline 3 & 26.4 & & \\
\hline 4 & 27.8 & & \\
\hline
\end{tabular}

Table 5 Hardness test results of welded joint specimen

\begin{tabular}{|c|c|c|c|}
\hline Specimens & Weld seam/HRC & Average & Standard request \\
\hline 1 & 27.6 & & \multirow{2}{*}{27.8} \\
\hline 2 & 28.1 & & \multirow{2}{*}{$26 \pm 2$} \\
\hline 3 & 28.4 & & \\
\hline 4 & 27.2 & & \\
\hline
\end{tabular}

From the table 4 it can be seen that the average hardness of U75V base metal is $27.0 \mathrm{HRC}$, it is in the range of $26 \pm 2$, which was given out by the standard TB/T 1632-1991. The average hardness of 
U75V welded joint is $27.8 \mathrm{HRC}$, it is also in the range of $26 \pm 2$, which was given out by the standard TB/T 1632-1991. From the table 4 and table 5 it can be concluded that the hardness of base metal and welded joints are all satisfied.

Microstructure and analysis. Microstructures after combustion synthesis welding was investigated by means of optical microscope of Axio Vert.A1 as shown in Fig. 2.

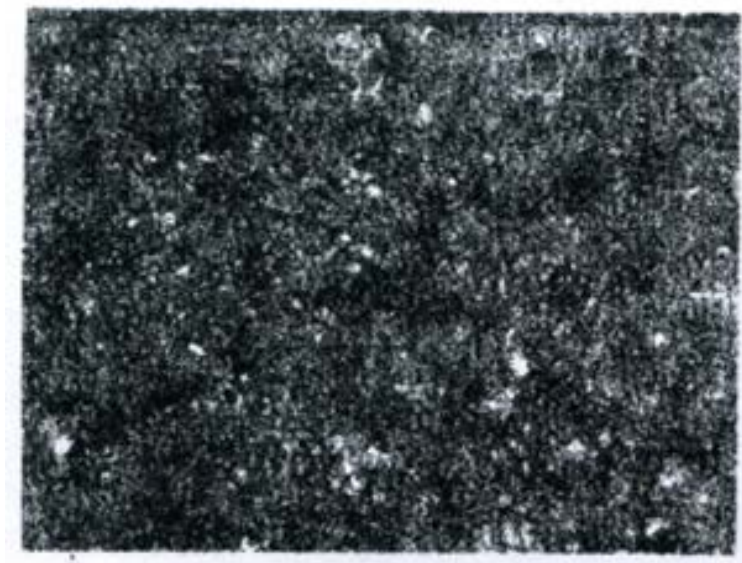

Fig. 2 The microstructure of welded joint

From the Fig. 2 it can be seen that the microstructure of combustion synthesis welding joint was pearlite and ferrite. The standard of TB/T 1632-1991 request that the martensite and widmanstatten structure after welding can not be permitted. That means the microstructure meets the requirement of the standard.

\section{Conclusions}

(1)The U75Vrail steel was successfully welded by using the combustion synthesis welding method. The microstructure in the welded joint is pearlite and ferrite, which meets the requirement of the standard.

(2)The tensile strength of the welded joint is $753 \mathrm{MPa}$, it is great than the request of the standard of TB/T 1632-1991(710MPa). The average elongation is $2.23 \%$, it is also great than that of the request of the standard of TB/T 1632-1991(2.0\%). The hardness of base metal and the welded joint are all satisfied.

\section{Acknowledgment}

The work is supported by the Science Foundation of East China Jiaotong University, and Natural Science Foundation of Jiangxi Province (No.20114BAB206020), Science Foundation of education office of Jiangxi Province (GJJ12302).

\section{References}

[1]Merzhanov A G:Combustion and Plasma Synthesis of High-temperature Materials. New York; VCH Publ. Inc.1990

[2]Shcherbakov V A: Key Engineering Marerials, Vol. 217 (2002), p.215

[3]Sheherbakov V A, Shteiberg A S: Inter. J. of SHS, Vol.2(1993), p.357

[4]Moore T J: Scripta Metallurgica et Material, Vol.30(1994), p.463

[5]Zhu D P, Liu W P: J welding, Vol.3 (2000), P.14

[6]Uenishi K, Matsubara T, Kobayashi K F: Z M etallkd, Vol.90(1999), P.163

[7]Yin S: Combustion synthesis. Metallurgical industry press, 2004(in Chinese) 